\title{
Performance of Environmental and Energy Audit for Manufacturing Industrial Buildings
}

\author{
Norfishah Ab Wahab ${ }^{1}$, N. A. Sahril ${ }^{2}$, A. Amiruddin ${ }^{3}$, Zuhaila Mat Yasin ${ }^{4}$, N. A. Salim ${ }^{5}$, \\ N. A. Rahmat $^{6}$, N. F. A. Aziz \\ ${ }^{1}$ Applied Electromagnetics Research Group, Faculty of Electrical Engineering, Universiti Teknologi MARA, 40450 Shah \\ Alam, Malaysia \\ ${ }^{2,4,5}$ Faculty of Electrical Engineering, Universiti Teknologi MARA, 40450 Shah Alam, Malaysia \\ ${ }^{6,7}$ Institute of Power Engineering, Electrical Power Department, College of Engineering, \\ Universiti Tenaga Nasional, Malaysia
}

\begin{tabular}{|c|c|}
\hline Article Info & ABSTRACT \\
\hline Article history: & Environmental and energy audit of industrial building is important as it may \\
\hline Received Jun 2, 2018 & $\begin{array}{l}\text { help in providing a comfortable workplace for the staff as well as to observe } \\
\text { the company's environmental practices during operational hours while }\end{array}$ \\
\hline Revised Jul 31, 2018 & managing the energy usage in an efficient manner. It is also important in \\
\hline Accepted Aug 11, 2018 & $\begin{array}{l}\text { ensuring the company comply with applicable laws and regulations This } \\
\text { paper discusses on the environmental and energy audit to identify the }\end{array}$ \\
\hline Keywords: & $\begin{array}{l}\text { performance of environmental and energy efficiency in two manufacturing } \\
\text { industrial buildings with heavy machineries. Analyses on the energy }\end{array}$ \\
\hline Audit & performance, visual comfort and thermal improvement including \\
\hline Building & environmental aspects of the two buildings are presented. Energy efficiency \\
\hline Energy & and environmental aspects covered in this audit study are the illuminance of \\
\hline Industrial & the building, indoor building temperature, relative humidity and carbon \\
\hline Environment & dioxide (CO2) percentage in indoor air quality. Jabatan Kerja Raya (JKR) \\
\hline Performance & $\begin{array}{l}\text { standards is used as a benchmark to observe the illuminance of the buildings, } \\
\text { Malaysian Standard } 1525 \text { (MS1525) is used as a quality control for } \\
\text { temperature and relative humidity, while Department of Occupational Safety } \\
\text { and Health, } 2005 \text { (DOSH 2005) is used as a quality control for CO2 } \\
\text { percentage in air. Based on the results from the audit, the performance for } \\
\text { both industrial building is compared. It was found that the energy efficiency } \\
\text { and environmental performance for Factory A is better than Factory B. }\end{array}$ \\
\hline
\end{tabular}

Copyright () 2018 Institute of Advanced Engineering and Science. All rights reserved.

\section{Corresponding Author:}

Norfishah Ab Wahab

Applied Electromagnetics Research Group,

Faculty of Electrical Engineering,

Universiti Teknologi MARA, 40450 Shah Alam, Malaysia.

Email: fishah@salam.uitm.edu.my

\section{INTRODUCTION}

Environmental audit which is part of energy audit process is essentially an environmental management tool for measuring the effects of certain activities on the environment against set criteria or standards depending on the types of standards and the focus of the audit. The outcome of the environment audit helps to improve existing human activities, with the aim of reducing the adverse effects of these activities on the environment. In industrial, there's need in doing auditing of energy and environment for buildings to avoid waste of energy besides as an assessment of environmental opportunities. This involves lighting, special equipment or machine that are used in their operation and air conditioning equipment including inefficient operation of air conditioning system due to doors and windows in air conditioned spaces 
left open [1-4]. Energy performance, visual comfort, and thermal improvement of industrial building sector are among the important criterias studied during audit process [5]. It is well known that energy audit is crucial to improve the energy efficiency of buildings by identifying opportunities to reduce energy consumption where the procedure undertaken will identify what, when, and how energy is used in a building. A standard energy audit consists of a comprehensive energy analysis for the energy systems of the facility. The standard audit goes on to quantify energy uses and losses through a more detailed review and analysis of equipment, systems, and operational characteristics. This analysis may also include some on-site measurement and testing to quantify energy use and efficiency of various systems [2]. Energy conservation in manufacturing industries can be done by the process of regular audit of plants and workshops through professional auditors, especially for equipment's including lighting lamps, air-conditioners, motors and elevators [3]. Lighting which is always the vital part of any and industrial load, plays a very important role in increasing the profit margin by energy conservation [6]. Approximately, lighting systems consumes $25 \%$ of electrical energy utilization in buildings [4]. Lighting provides us the opportunity to implement cost effective saving measures without a substantial modification in the existing design. $70 \%$ to $80 \%$ of electricity bills are affected by bulbs hence illumination improvements are an excellent investment to be carried out [7]. Air conditioning consumes the highest electrical energy in buildings with approximately $56 \%$ of the electrical energy utilization in buildings. The use of efficient air conditioning system can reduce equipment losses and improve system efficiency [8-9].

In this paper, an audit was executed to identify and compare the performance of environmental and energy efficiency in two manufacturing industrial buildings which are Factory A and Factory B, to analyze energy performance, visual comfort and thermal improvement and to recommend solutions to optimize the energy efficiency and environmental aspects of the two buildings. Energy efficiency and environmental aspects covered in this audit are the illuminance of the building, indoor building temperature, relative humidity and $\mathrm{CO} 2$ percentage in indoor air quality. The lighting and air-conditioning system are taken into consideration for identification of energy usage in the factories. Jabatan Kerja Raya (JKR) standards is used for illuminance audit, Malaysian Standard 1525 (MS1525) for temperature and relative humidity, while Department of Occupational Safety and Health, 2005 (DOSH 2005) standard is refered for quality control of $\mathrm{CO} 2$ percentage in air. Analyses on the data for all parameters and the results obtained are presented. The results may aid the organization to take actions in providing healthier working surrounding as well as reducing the unnecessary operation expenses.

\section{RESEARCH METHOD}

This project started with primary site survey and preparation required for detail auditing. The scope of audit for both factories is in the area of energy and environmental. The parameters for the auditing are illuminance, indoor building temperature, relative humidity and the concentration of CO2 in air quality. The audit results are then compared with suitable standards practically used in Malaysia. Locations selected for this project are two manufacturing industrial buildings in Shah Alam, Selangor Malaysia. On-site audit was conducted with a visit to the first manufacturing industrial building which is Factory A. The area of the factory is divided into few sections based on the floor plan given to obtain average measurement of each parameters. Measurement of illuminance, indoor building temperature, relative humidity and $\mathrm{CO} 2$ in air were taken at each section. The same processes are applied to Factory B. Both on-site audits were done in the morning from 10.00 a.m. to 12.00 p.m. on a ddifferent working day. In data analysis, the parameters with values and trends that deviate from standards are viewed and spotted. Jabatan Kerja Raya Malaysia (JKR) standards. For each factory, the illuminance is analyzed at two different level based on the working nature of the region since different work activities requires different level of illuminance. However, indoor temperature, relative humidity and value of carbon dioxide in air are analysed at a level which comprised one single region for each company since all these parameters are not affected by different kind of working nature. Malaysian Standards 1525 (MS1525) is used to set the standards value for indoor temperature and relative humidity of the factories. While Department of Occupational Safety and Health 2005 (DOSH 2005) is used to set the concentration of $\mathrm{CO} 2$ in air.

\subsection{Building Description for Factory A}

Factory A is a manufacturing company that design and manufacture Super Twisted Nematic (STN) LCD, located in Subang, Selangor Malaysia with 24 hours of operating hour. This company has three levels of building which consists of manufacturing and office area with auditing process covered only the manufacturing area. The whole ground level which is used for manufacturing process is without daylight exposure. The floor area of ground level is around $49000 \mathrm{~m}^{2}$. The area is divided into 36 sections with 20 sections are identified as Region A (i) and 16 sections as Region A (ii) based on the type of manufacturing 
activities. As shown in Figure 1, the unshaded region is denoted as Region A (i) for fine work activities while the shaded region is Region A (ii) for machinery work and ordinary automatic machines.

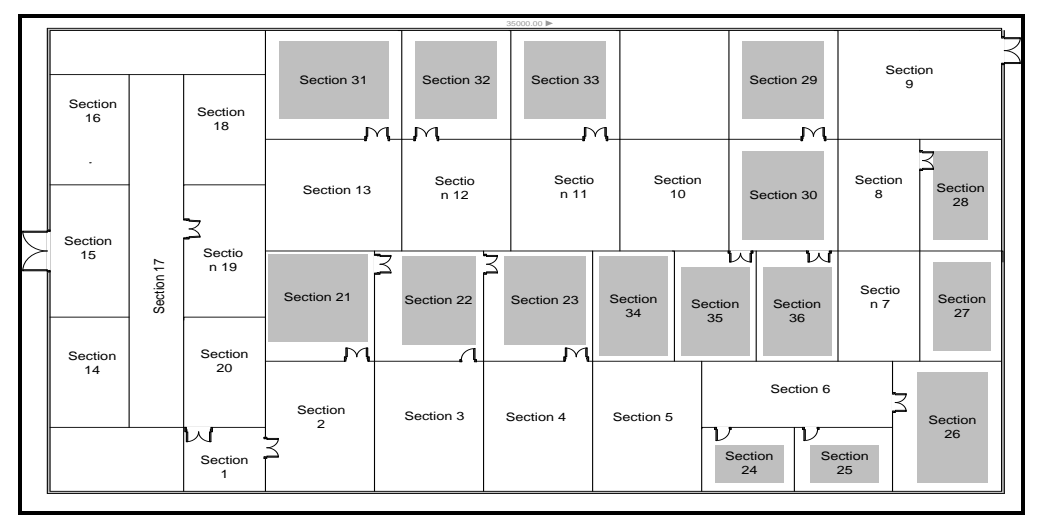

Figure 1. Factory A: Floor plan of manufacturing area

\subsection{Building Description for Factory B}

Factory B is a manufacturing company, located in Shah Alam, Selangor Malaysia, produces copper tube for fabricated products with 24 hours operating hour. This two levels building consists of manufacturing and office areas with auditing process covered only the manufacturing area. The floor area around $63000 \mathrm{~m}^{2}$, the manufacturing area are divided into 27 sections. These sections are divided into two Regions according to type of manufacturing activities in the factory. 10 sections are identified as Region B(i) and 17 sections as Region B(ii). As shown in Figure 2, the unshaded region is denoted for Region B (i) to cater rough bench and machine work while the shaded region is Region B(ii) for metal works such as pressing, stamping, folding, shearing and medium soldering.

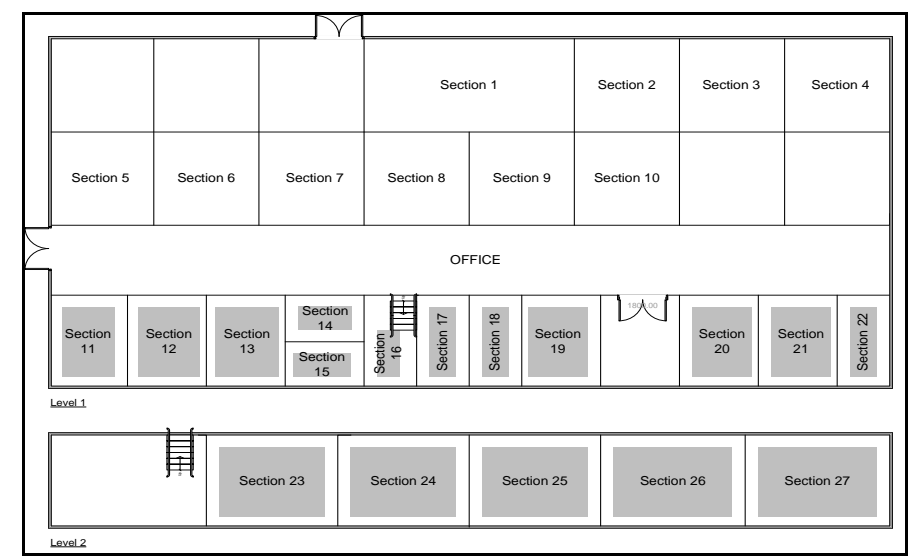

Figure 2. Factory B: Floor plan of manufacturing area

\section{RESULTS AND ANALYSIS}

\subsection{Factory a Data Analysis}

\section{a) Illuminance}

Figure 3 shows the average measured illuminance level for Region A (i). This region is defined for fine work activity that requires 600 lux of illuminance according to Jabatan Kerja Raya (JKR) standards. Only three sections meet the standard. Section 15 has over range of illuminance meanwhile for the rest of the sections, the illuminance levels are lower than 600 lux. This causing insufficient of brightness for fine work activities. Figure 4 reports the illuminance level for Region A(ii), which are machinery work and ordinary automatic machine areas. These areas require 400 lux of illuminance based on JKR standards. As can be seen, seven sections are below the range of suitable illuminance. These sections are 21, 22, 24, 26, 31,32 and 
33. Two sections which are 23 and 29 almost meet the perfect illuminance for machinery work. Sections 27 , 28 and 36 managed to achieve 400 lux of illuminance while sections 25, 30, 34 and 35 exceeded the illuminance level. Based on Figure 5, only the temperature in sections 5 and 13 are above maximum standards while sections 18, 19, 20 and 29 are below minimum standards of comfortable temperature. The rest of the sections meet the standards of Malaysian Standards 1525(MS 1525), that is in between the range of $23^{\circ} \mathrm{C}$ to $27^{\circ} \mathrm{C}$.

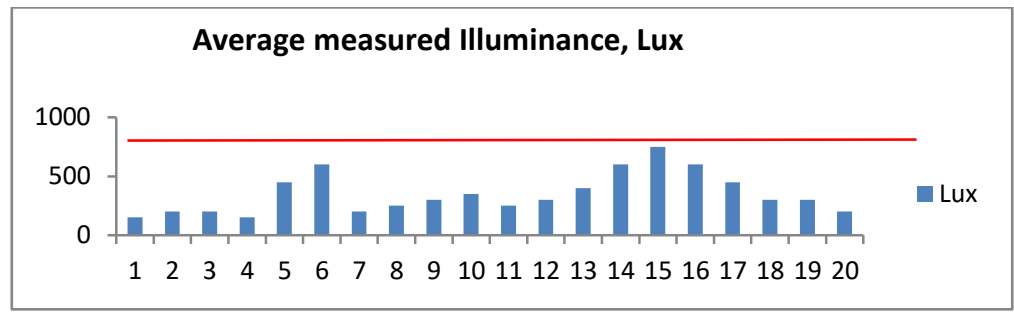

Figure 3. Factory A: Average measured illuminance of each sections in Region A (i)

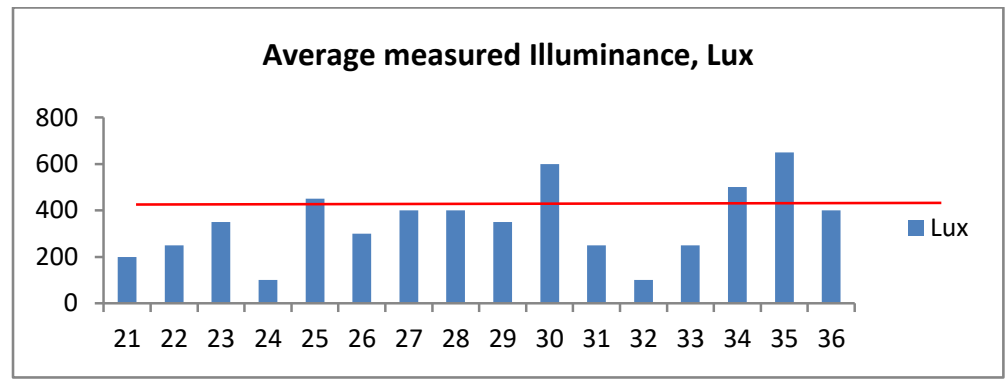

Figure 4. Factory A: Average measured illuminance of each sections in Region A (ii)

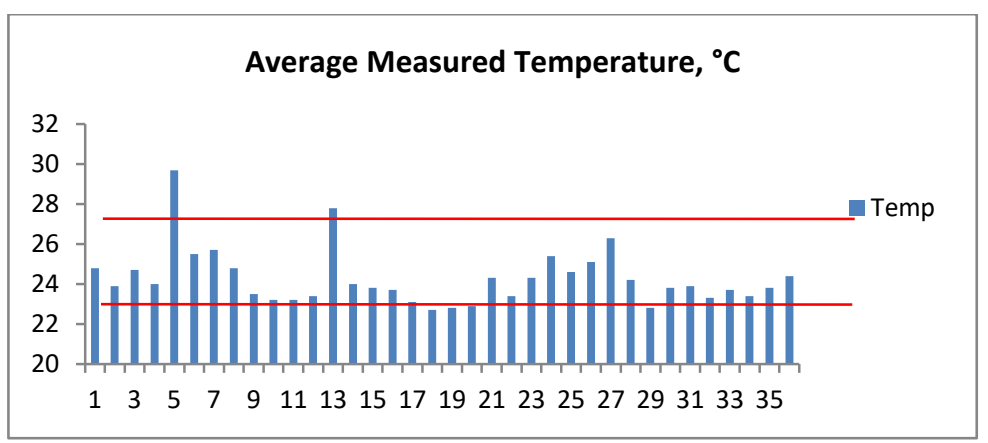

Figure 5. Factory A: Average measured temperature of each sections

\section{b) Relative Humidity}

Figure 6 shows that sixteen sections are within standards of relative humidity which in the range of $55 \%$ to $70 \%$. Section 24 is over range from standard and another nineteen sections did not meet the minimum standards of relative humidity in buildings.

c) $\mathrm{CO} 2$ in Air

As shown in Figure 7, all the sections in the manufacturing areas showed that the levels of $\mathrm{CO} 2$ in Factory A are below 1000 ppm hence meeting the standard of air quality for indoor building.

d) Percentage of each element at Factory A

As shown in Figure 8, the percentage of illuminance measurement result has shown $16.67 \%$ of audit points meet the illuminance standards for manufacturing activities in a building. $69.44 \%$ of illuminance does not meet the minimum standards of perfect illumination and another $13.89 \%$ of audit points has illuminance 
higher than maximum standards. In terms of temperature, $11.11 \%$ of audit points is too cold as the temperature recorded is under range, $83.33 \%$ of the audit points are within the range while $5.56 \%$ exceeded the maximum temperature set by MS 1525 . In terms of relative humidity, $44.44 \%$ meet the range of suitable humidity accordance to MS 1525 . Meanwhile, $52.78 \%$ of audit points is under range and $2.78 \%$ is over range. Lastly, Factory A is efficiently reaches the standard of DOSH 2005 for CO2 percentage which shows that it has good air quality.

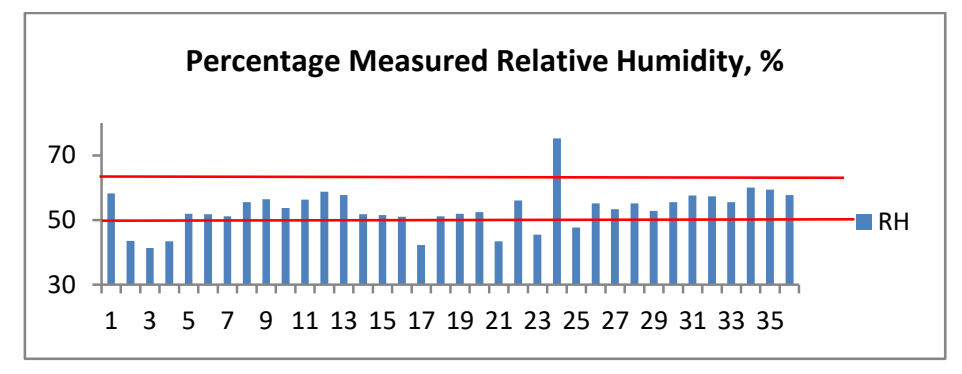

Figure 6. Factory A: Average measured relative humidity of each sections

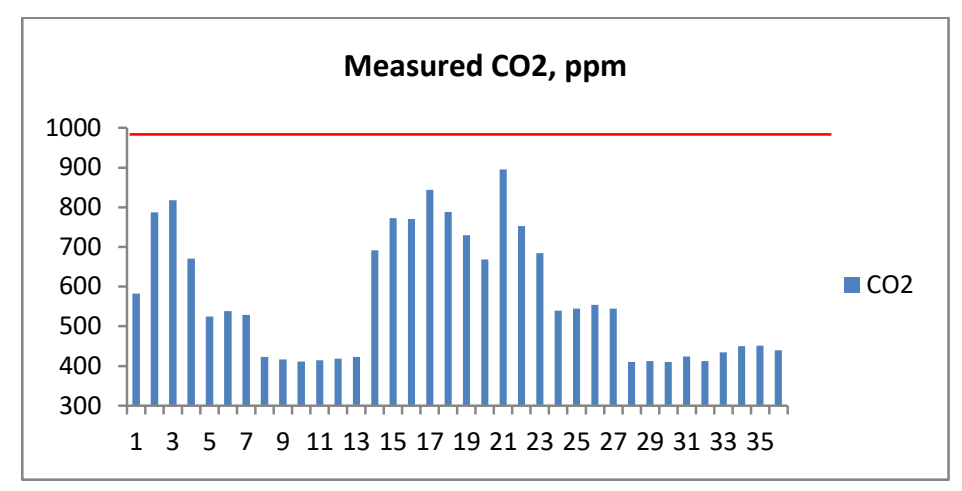

Figure 7. Factory A: Average measured $\mathrm{CO} 2$ of each sections indoor building

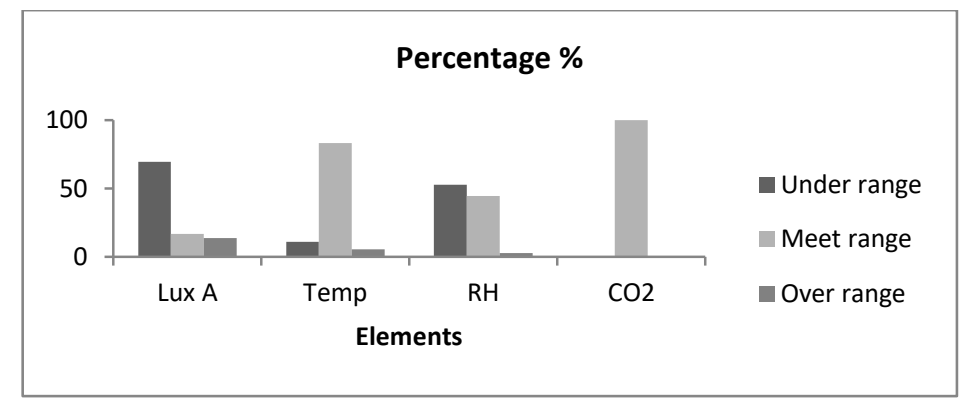

Figure 8. Factory A: Percentage of each element

\subsection{Factory B Data Analysis}

a) Illuminance

Based on Figure 9, the average illuminance in Factory B is inconsistent throughout the sections. Region $\mathrm{B}(\mathrm{i})$ is the region consists of rough bench and machine, where this activity requires 200 lux of illuminance for perfect lighting. In sections 1 until 8, the average illuminance is below the standard (too dark) and therefore the illuminance does not fit with the scope of activity performed in these sections. At sections 9 and 10, the illuminance meets perfect range which is within 200 lux. The illuminance from all sections shows that the existing lighting system cannot deliver sufficient amount of illuminance through all over the manufacturing area. 


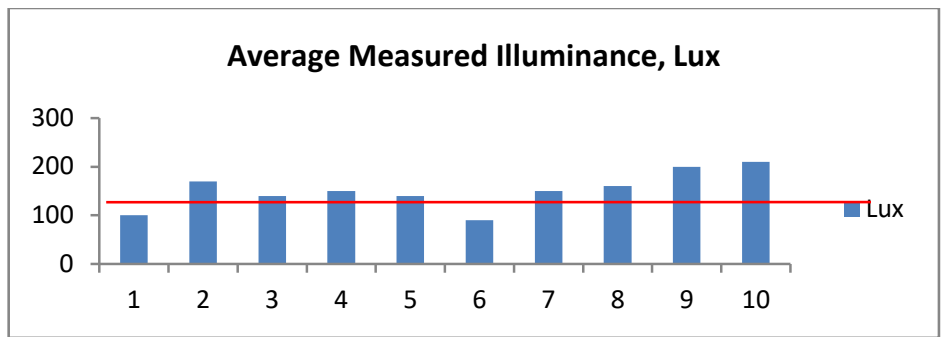

Figure 9. Factory B: Average measured illuminance of each sections in Region B (i)

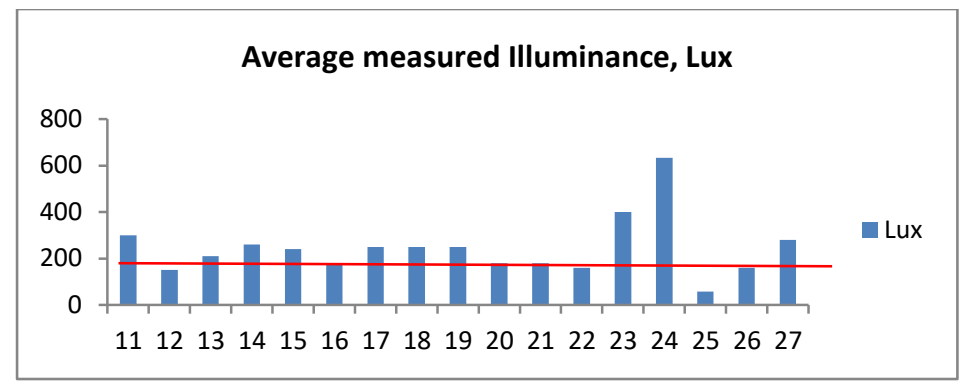

Figure 10. Factory B: Average measured illuminance of each sections in Region B (ii)

Figure 10 shows that the average illuminance are not consistent throughout the sections. The nature of work in Region B(ii) consists of metal works such as pressing, stamping, folding, shearing and medium soldering and requires 300 lux of illuminance based on JKR standards. In sections 12, 13, 16, 20, 21, 22, 25 and 26; the average illuminances are below standard (too dark), and does not fit with the scope of activities. In sections $14,15,17,18,19$, and 27 , the average illuminances are close to perfect illuminance and may not give too much disturbance to the workers. Section 11 meet the standard for metal work while sections 23 and 24 exceeded the required standard.

b) Indoor Temperature

Figure 11 shows that the whole manufacturing area of Factory B did not meet the range for temperature based on MS 1525 , that is in the range of $23^{\circ} \mathrm{C}$ to $27^{\circ} \mathrm{C}$. It can be seen that the temperatures are above $30^{\circ} \mathrm{C}$.

c) Relative Humidity

Figure 12 shows that all sections in the manufacturing area meet the standards of relative humidity according to MS 1525, which is in the range of 55\% to 70\%, except for sections 13, 14, 15 and 16 . Those four sections have a very low humidity and did not meet the required standard.

d) $\mathrm{CO} 2$ in Air

Based on Figure 13, all sections at Factory B meet the standard of air quality indoor building where CO2 must be below 1000 ppm according to Department of Occupational Safety and Health, 2005 (DOSH 2005).

e) Percentage of each element at Factory B

Refer to Figure 14, it is found that the illuminance level does not meet the standard set by JKR Malaysia, with $81.48 \%$ of audit points are under range while $11.11 \%$, exceed the range (over range). Only $7.41 \%$ of audit points meet the required illuminance for manufacturing activity in the factory. For temperature level, it shows over range for all manufacturing areas, while for relative humidity, most of the manufacturing areas meet the range according to MS 1525 that is between $55 \%$ to $70 \%$; and $14.81 \%$ of audit points are under range. For air quality level, the factory meets the requirement of air quality standard according to DOSH 2005, with less than 1000ppm of CO2 contained in air for all manufacturing areas. 


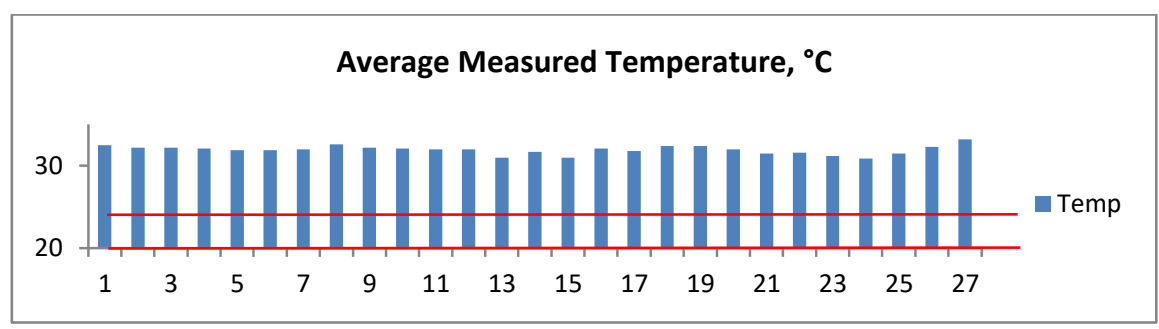

Figure 11. Factory B: Average measured temperature of each sections

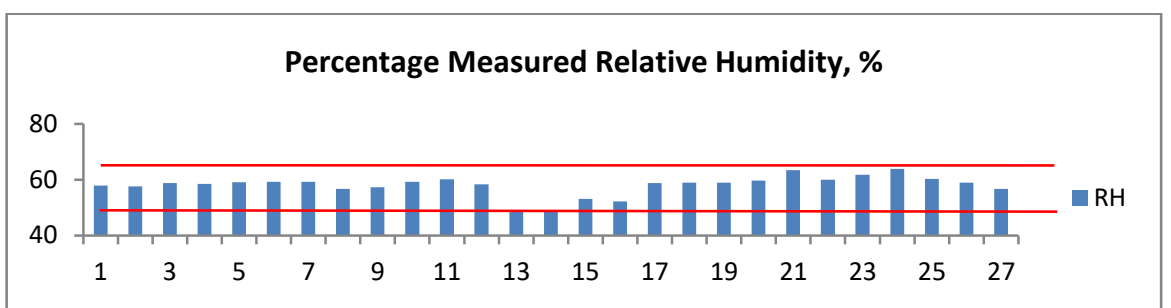

Figure 12. Factory B: Average measured relative humidity of each sections

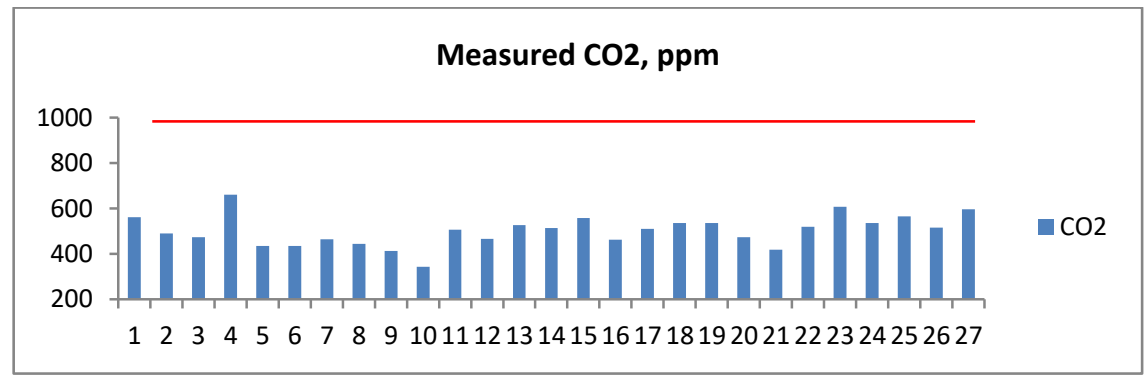

Figure 13. Factory B: Average measured $\mathrm{CO} 2$ of each sections for indoor building

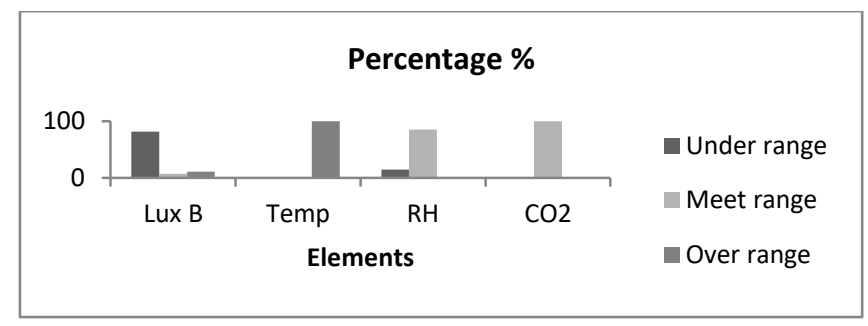

Figure14. Factory B: Percentage of each element

\section{CONCLUSION}

Throughout the auditing process, the illuminance in Factory A was inconsistent with most of the areas were below the minimum. This may be improved by replacing the fluorescent lamp at the work stations with Light Emitting Diode (LEDs) lamp as the LED lamp are smaller in size, high reliability, long life, provides environmental protection and energy saving. In terms of indoor building temperature, most of the manufacturing area recorded temperature within the range of $23^{\circ} \mathrm{C}$ to $27^{\circ} \mathrm{C}$ thus following Malaysian Standards 1525 (MS 1525). As for the level of $\mathrm{CO} 2$, this factory fulfilled the standards of air quality as referred to DOSH 2015. For Factory B, it was found that most of the manufacturing areas had illuminance below Jabatan Kerja Raya (JKR) standards. Enhancement of the illuminance are needed as the current lighting condition may give bad effect on health and job performance of the workers in the factory. The 
indoor temperature in all areas exceeded the maximum standard according to Malaysian Standards 1525 (MS 1525). Meanwhile, for relative humidity, more than half of the manufacturing areas did not comply to the standard. As for the level of CO2, the factory fulfilled the standards of air quality as referred to DOSH 2015. In terms of environment, green building practices can be introduced for both factories as an alternative for lighting and cooling system in order to improve natural ventilation, daylight exposure and also the energy consumption. The application of daylight exposure may also reduce peak-cooling load by $10 \%$ and $13 \%$ of the annual electricity consumption [5]. In order to achieve thermal comfort without mechanical cooling, most efficient building use natural ventilation and solar protection system [10].

\section{ACKNOWLEDGMENT}

This work was supported by the Ministry of Education Malaysia, under Niche Research Grant Scheme (NRGS) [600-RMI/NRGS 5/3 (3/2013)] and the Faculty of Electrical Engineering, Universiti Teknologi MARA (UiTM), Shah Alam, Malaysia

\section{REFERENCES}

[1] C S Tan, K Maragatham, Y P Leong,” Electricity Energy Outlook in Malaysia “, 4th International Conference on Energy and Environment, 2013.

[2] J. Gomes, D. Coelho, and M. Valdez, "Energy Audit in a School Building Technology, Professional and Artistic School of Pombal", IEEE.

[3] R. Shankar, "Energy Auditing in Electrical Utilities Viva Books 2010".

[4] Harapajan Singh, Manjeevan Seera, Mohamad Adha Mohamad Idin," Electrical Energy Audit in a Malaysian University", IEEE International Conference on Power and Energy (PECon), 2012.

[5] Adi Ainurzaman Jamaludin, Nila Inangda, Ati Rosemary Mohd Ariffin, and Hazreena Hussein," Energy Performance: A Comparison of Four Different Multi-Residential Building Designs and Forms in the Equatorial Region”, 2011 IEEE First Conference on Clean Energy and Technology CET, 2011.

[6] Muhammad Usman Khalid, Mariam Gul, Muhammad Mohsin Aman, Ahsan Hashmi, "Energy Conservation through Lighting Audit”, IEEE International Conference on Power and Energy (PECon), 2012.

[7] D. H. W. Li and E. K. W. Tsang, "An analysis of measured and simulated daylight illuminance and lighting savings in a daylit corridor," Building and Environment, vol. 40, pp. 973-982, 2005.

[8] H.E. Hua, L. Tian-yu, Z. Zhi-yong, and Z. Juan, "Energy Saving Potential of a Public Building in Jiangbei District of Chongqing," International Conference on Management and Service Science, 2009.

[9] N Y Dahlan, M S Shaari, T A N T Putra, S M Mohd Shokri, Hasmaini Mohammad, "Energy and Environmental Audit for Bangunan Menara Seri Wilayah and Bangunan Kastam, Putrajaya: Analysis and Recommendations", IEEE Conference on Clean Energy and Technology (CEAT), 2013.

[10] C. Candido, RJ. de Dear, R. Lamberts, L. Bittencourt, "Air movement acceptability and thermal comfort in Brazil's hot humid climate zone," Build. Env. 45, 2010, pp.222-229. 